\title{
Antimicrobial Resistance of Salmonella enterica Isolates from Tonsil and Jejunum with Lymph Node Tissues of Slaughtered Swine in Metro Manila, Philippines
}

\author{
Kamela Charmaine S. $\mathrm{Ng}^{1}$ and Windell L. Rivera ${ }^{1,2}$ \\ ${ }^{1}$ Institute of Biology, College of Science, University of the Philippines, Diliman, Quezon City 1101, Philippines \\ ${ }^{2}$ Natural Sciences Research Institute, University of the Philippines, Diliman, Quezon City 1101, Philippines \\ Correspondence should be addressed to Windell L. Rivera; wlrivera@science.upd.edu.ph
}

Received 1 January 2014; Accepted 27 January 2014; Published 4 March 2014

Academic Editors: C. M. A. Khan, T. Krishnan, and V. L. Traina-Dorge

Copyright ( $\odot 2014$ K. C. S. Ng and W. L. Rivera. This is an open access article distributed under the Creative Commons Attribution License, which permits unrestricted use, distribution, and reproduction in any medium, provided the original work is properly cited.

\begin{abstract}
Due to frequent antibiotic exposure, swine is now recognized as potential risk in disseminating drug-resistant Salmonella enterica strains. This study thus subjected 20 randomly selected S. enterica isolates from tonsil and jejunum with lymph node (JLN) tissues of swine slaughtered in Metro Manila, Philippines, to VITEK 2 antimicrobial susceptibility testing (AST). The test revealed all 20 isolates had resistance to at least one antimicrobial agent, in which highest occurrence of resistance was to amikacin (100\%), cefazolin (100\%), cefuroxime (100\%), cefuroxime axetil (100\%), cefoxitin (100\%), and gentamicin (100\%), followed by ampicillin (50\%), and then by sulfamethoxazole trimethoprim (30\%). Three multidrug-resistant (MDR) isolates were detected. The sole S. enterica serotype Enteritidis isolate showed resistance to 12 different antibiotics including ceftazidime, ceftriaxone, amikacin, gentamicin, and tigecycline. This study is the first to report worldwide on the novel resistance to tigecycline of MDR S. enterica serotype Enteritidis isolated from swine tonsil tissues. This finding poses huge therapeutic challenge since MDR $S$. enterica infections are associated with increased rate of hospitalization or death. Thus, continual regulation of antimicrobial use in food animals and prediction of resistant serotypes are crucial to limit the spread of MDR S. enterica isolates among hogs and humans.
\end{abstract}

\section{Introduction}

Salmonella is a rod-shaped, Gram-negative, oxidase negative, nonspore forming, predominantly peritrichous enterobacterium [1]. It has been reported and recognized as one of the leading causes of food borne illness, causing diarrheal diseases and enteric fever that may be complicated by extraintestinal infections, such as bacteremia, meningitis, and osteomyelitis, leading to millions of cases of hospitalizations and deaths worldwide each year $[2,3]$. It has been isolated from a wide variety of animals, of which swine are the most commonly recognized carriers [4].

The demand for the production of quality livestock meat is increasing. However, the hog livestock production system, despite being the top livestock industry in the Philippines, is constantly challenged with various microbial diseases such as salmonellosis that lead to morbidity-linked reduction in productivity and increased cost of disease treatment [5]. The threat and prevalence of this disease in the country continue to be high [6]. Food poisoning outbreaks and livestock infection caused by Salmonella spp. are widespread in the Philippines as evidenced by cases of food poisoning reported in Benguet, Tondo, Manila, and Bulacan and cases of hog morbidity and mortality in Tacloban and Leyte [6-9].

The widespread use of antibiotics has resulted in the emergence of drug-resistant Salmonella strains. Since antibiotics are widely used for growth promotion and disease treatment in commercial swine production systems, swine is now recognized as a potential risk in disseminating multidrug-resistant (MDR) Salmonella spp. strains $[4,10,11]$. The VITEK 2 system (bioMerieux) has revolutionized antimicrobial susceptibility testing through its rapid and automated fluorescence-based technology. Livermore and coworkers [12] have commended the accuracy of identification and antimicrobial susceptibility testing (AST) of the VITEK 2 
system and the significantly reduced handling time that enhances the work flow of clinical microbiology laboratory.

This study aimed to characterize $S$. enterica isolates from tonsil and jejunum with lymph node (JLN) tissues of swine at slaughter in selected accredited and non-accredited meat establishments in Metro Manila. In order to detect MDR strains and shed light on the appropriate treatment against the pathogen, VITEK 2 AST was performed in this study.

\section{Materials and Methods}

2.1. Sample Collection. Tonsils and their corresponding JLN tissues were collected from 30 hogs in each of the four nonaccredited meat establishments in Quezon City and four accredited slaughterhouses in Malabon, Makati, Pasig, and Quezon City in Metro Manila, Philippines. A $15 \mathrm{~cm}$ long segment of JLN was secured with sterile threads on both ends and excised with the flame sterilized knife of the butcher. It was immediately transferred to a sterile bag that was cooled during transport to the laboratory. Afterwards, $25 \mathrm{~g}$ of JLN was weighed in a sterile foil and pre-enriched with $225 \mathrm{~mL}$ of buffered peptone water in a sterile bottle, agitated for $2 \mathrm{~min}$, and incubated for $18-24 \mathrm{~h}$ at $37^{\circ} \mathrm{C}$. The tonsil tissues were collected using flame sterilized forceps and butcher's knife and were pre-enriched the same way as the intestinal samples.

2.2. Single-Enrichment Broth Culture Method. One hundred microliters of pre-enriched tonsil tissue and JLN samples were inoculated into Rappaport-Vassiliadis Broth $(10 \mathrm{~mL})$ while one $\mathrm{mL}$ of the pre-enriched samples was inoculated into Tetrathionate Broth $(10 \mathrm{~mL})$ and was incubated at $37^{\circ} \mathrm{C}$ for $24 \mathrm{~h}$. After incubation, broth cultures were streak-plated onto selective, chromogenic medium, Rainbow Agar Salmonella (RAS).

2.3. DNA Extraction. Three colonies of Salmonella spp. cells from RAS were suspended in $150 \mu \mathrm{L}$ of sterile distilled water. The suspension was heated at $100^{\circ} \mathrm{C}$ for $10 \mathrm{~min}$ and cooled to room temperature afterwards. The cell debris was pelleted by centrifugation at 13,000 rpm for $2 \mathrm{~min}$. The clear supernatant obtained was used as DNA template in PCR [14]. Concentration of DNA extracts was then measured using NanoDrop 2000 following the manufacturer's instructions.

2.4. PCR-Based Identification of Salmonella spp. Isolates. InvA primers, invA-F and invA-R, which amplify a $244 \mathrm{bp}$ fragment of the invA gene specific for Salmonella spp. were used for initial detection and confirmation of suspected Salmonella spp. isolates [15]. Promega GoTaq Green Master Mix consisting of GoTaq DNA polymerase, 2X Green GoTaq Reaction Buffer, $3 \mathrm{mM} \mathrm{MgCl}_{2}$, and $0.4 \mathrm{mM}$ dNTPs was used for PCR amplification of invA region. DNA amplification was performed in a reaction volume of $25 \mu \mathrm{L}$. PCR was performed under the following cycling conditions: an initial denaturation at $95^{\circ} \mathrm{C}$ for $2 \mathrm{~min}$, followed by 35 cycles of denaturation at $95^{\circ} \mathrm{C}$ for $30 \mathrm{~s}$, annealing at $56^{\circ} \mathrm{C}$ for $30 \mathrm{~s}$, and extension at $72^{\circ} \mathrm{C}$ for $2 \mathrm{~min}$. Final extension was done at $72^{\circ} \mathrm{C}$ for $5 \mathrm{~min}$. For each run, DNA from $S$. enterica serotype
Typhimurium was used as positive control while sterile water as template was included as negative control.

Amplicons were checked by separating PCR products through agarose gel electrophoresis in 1x TAE buffer at 100 volts for 30 to $40 \mathrm{~min}$. All PCR products were analyzed in a $1.5 \%$ agarose gel stained with $0.5 \mu \mathrm{g} / \mathrm{mL}$ ethidium bromide for 20 min and visualized on a UV transilluminator. The sizes of the bands were estimated using Vivantis 1000 bp DNA ladder as molecular weight marker.

2.5. DNA Sequencing of Selected Amplicons. PCR products obtained with the primers representing each serogroup were sent to Macrogen, Inc. (Seoul, South Korea) for purification and DNA sequencing for validation of their identities. Nucleotide sequence data obtained were checked in BioEdit v. 7.0.9.0 sequence alignment program [16] and compared to available sequences of Salmonella spp. in GenBank using the Basic Local Alignment Search Tool (BLAST) algorithm available in the National Center for Biotechnology Information website (http://www.ncbi.nlm.nih.gov/BLAST).

2.6. Antimicrobial Susceptibility Testing. VITEK 2 AST of 20 randomly selected $S$. enterica isolates from slaughtered swine in both accredited and non-accredited meat establishments was performed to generate the antibiograms and detect MDR strains (Table 1). The stock culture strains were subcultured onto Salmonella-Shigella agar plates to confirm their purity. The turbidity of the bacterial suspensions was adjusted with a densitometer (DENSICHEK) to match that of a McFarland $0.4-0.6$ standard in $0.45 \%$ sterile sodium chloride solution. The time interval between suspension preparation and card filling was less than $30 \mathrm{~min}$ to avoid changes in turbidity. Afterwards, the VITEK 2 AST N091 antimicrobial susceptibility cards and bacterial suspension in tubes, both contained in a cassette, were manually loaded into the VITEK 2 system. Each test card was automatically filled with a bacterial suspension, sealed, incubated, and read by kinetic fluorescence measurement. The reporting time for the direct testing of susceptibility against the 17 antibiotics for 20 swine tissue culture isolates by the VITEK 2 system ranged from 8.5 to 10.5 hours.

\section{Results}

VITEK 2 AST of 20 randomly selected S. enterica isolates from slaughtered swine in Metro Manila, Philippines (Table 1) revealed that all had resistance to at least one antimicrobial agent, in which highest occurrence of resistance was to amikacin (100\%), cefazolin (100\%), cefuroxime (100\%), cefuroxime axetil (100\%), cefoxitin (100\%), and gentamicin (100\%), followed by ampicillin (50\%), and then by sulfamethoxazole trimethoprim (30\%). Tables 2(a) and 2(b) show the complete antibiogram of S. enterica isolates generated through VITEK 2 AST while Tables 3 and 4 reflect the distribution of in vitro and in vivo antimicrobial resistance, respectively, of $S$. enterica serotypes detected. As seen in Tables 2(a) and 2(b), four S. enterica serotype Typhimurium isolates, the sole serotype Heidelberg, one 
TABLE 1: Sequence similarities (\%) of isolates and reference Salmonella enterica sequences obtained from GenBank.

\begin{tabular}{|c|c|c|c|c|c|c|}
\hline Isolate & Region & Serogroup & Strain & Accession number & $\begin{array}{l}\text { Query length } \\
\text { and cover, } E \\
\text { value } \\
\end{array}$ & $\begin{array}{l}\text { \% Maximum } \\
\text { identity }\end{array}$ \\
\hline Lt16 & $\mathrm{rfbJ}$ & B & $\begin{array}{c}\text { Salmonella enterica subsp. } \\
\text { enterica serotype } \\
\text { Typhimurium str. U288 }\end{array}$ & СР003836.1 & $677,97 \%, 0.0$ & $99 \%$ \\
\hline Lt21 & $\mathrm{rfbJ}$ & B & $\begin{array}{c}\text { Salmonella enterica subsp. } \\
\text { enterica serotype } \\
\text { Typhimurium str. U288 }\end{array}$ & СР003836.1 & $671,98 \%, 0.0$ & $99 \%$ \\
\hline Lt24 & $\mathrm{rfbJ}$ & B & $\begin{array}{c}\text { Salmonella enterica subsp. } \\
\text { enterica serotype } \\
\text { Typhimurium str. U288 }\end{array}$ & СР003836.1 & $653,99 \%, 0.0$ & $99 \%$ \\
\hline Lt30 & $\mathrm{rfbJ}$ & B & $\begin{array}{c}\text { Salmonella enterica subsp. } \\
\text { enterica serotype } \\
\text { Typhimurium str. U288 }\end{array}$ & СР003836.1 & $686,95 \%, 0.0$ & $99 \%$ \\
\hline Lail & $\mathrm{rfbJ}$ & B & $\begin{array}{c}\text { Salmonella enterica subsp. } \\
\text { enterica serotype Agona str. } \\
\text { SL } 483\end{array}$ & СР001138.1 & $674,98 \%, 0.0$ & $99 \%$ \\
\hline Lai27 & $\mathrm{rfbJ}$ & B & $\begin{array}{c}\text { Salmonella enterica subsp. } \\
\text { enterica serotype } \\
\text { Typhimurium str. U288 }\end{array}$ & СР003836.1 & $672,95 \%, 0.0$ & $99 \%$ \\
\hline Lat23 & $\mathrm{rfbJ}$ & B & $\begin{array}{c}\text { Salmonella enterica subsp. } \\
\text { enterica serotype Agona str. } \\
\text { SL483 }\end{array}$ & СР001138.1 & $678,97 \%, 0.0$ & $99 \%$ \\
\hline Lat27 & $\mathrm{rfbJ}$ & B & $\begin{array}{c}\text { Salmonella enterica subsp. } \\
\text { enterica serotype Agona str. } \\
\text { SL483 }\end{array}$ & СР001138.1 & $665,97 \%, 0.0$ & $99 \%$ \\
\hline Lbt30 & $\mathrm{rfbJ}$ & B & $\begin{array}{c}\text { Salmonella enterica subsp. } \\
\text { enterica serotype } \\
\text { Typhimurium str. U288 }\end{array}$ & СР003836.1 & $684,97 \%, 0.0$ & $99 \%$ \\
\hline $\operatorname{Lct} 47$ & $\mathrm{rfbJ}$ & B & $\begin{array}{c}\text { Salmonella enterica subsp. } \\
\text { enterica serotype } \\
\text { Typhimurium str. U288 }\end{array}$ & СР003836.1 & $674,93 \%, 0.0$ & $100 \%$ \\
\hline $\mathrm{Nt} 4$ & $\mathrm{rfbJ}$ & B & $\begin{array}{c}\text { Salmonella enterica subsp. } \\
\text { enterica serotype } \\
\text { Typhimurium str. U288 }\end{array}$ & СР003836.1 & $684,94 \%, 0.0$ & $99 \%$ \\
\hline Pt26 & $\mathrm{rfbJ}$ & B & $\begin{array}{c}\text { Salmonella enterica subsp. } \\
\text { enterica serotype } \\
\text { Heidelberg str. B182 }\end{array}$ & СР001120.1 & $662,98 \%, 0.0$ & $99 \%$ \\
\hline Lat20 & wzxC1 & $\mathrm{Cl}$ & $\begin{array}{c}\text { Salmonella enterica subsp. } \\
\text { enterica serotype } \\
\text { Choleraesuis str. SC-B67 }\end{array}$ & AE017220.1 & $490,99 \%, 0.0$ & $99 \%$ \\
\hline Lbt18 & wzxC1 & $\mathrm{C} 1$ & $\begin{array}{c}\text { Salmonella enterica subsp. } \\
\text { enterica serotype } \\
\text { Choleraesuis str. SC-B67 }\end{array}$ & AE017220.1 & $487,99 \%, 0.0$ & $99 \%$ \\
\hline Lt25 & tyv & $\mathrm{D}$ & $\begin{array}{c}\text { Salmonella enterica subsp. } \\
\text { enterica serotype } \\
\text { Enteritidis str. P125109 }\end{array}$ & AM933172.1 & $619,99 \%, 0.0$ & $99 \%$ \\
\hline Li16 & wzxE1 & $\mathrm{E}$ & $\begin{array}{l}\text { Salmonella enterica subsp. } \\
\text { enterica serotype } \\
\text { Weltevreden str. } \\
\text { 2007-60-3289-1 }\end{array}$ & FR775224.1 & $\begin{array}{c}344,100 \% \\
2 e-176\end{array}$ & $99 \%$ \\
\hline Lt3 & wzxE1 & $\mathrm{E}$ & $\begin{array}{l}\text { Salmonella enterica subsp. } \\
\text { enterica serotype } \\
\text { Weltevreden str. } \\
\text { 2007-60-3289-1 }\end{array}$ & FR775224.1 & $\begin{array}{c}357,69 \% \\
4 e-115\end{array}$ & $98 \%$ \\
\hline
\end{tabular}


TABle 1: Continued.

\begin{tabular}{|c|c|c|c|c|c|c|}
\hline Isolate & Region & Serogroup & Strain & Accession number & $\begin{array}{l}\text { Query length } \\
\text { and cover, } E \\
\text { value }\end{array}$ & $\begin{array}{l}\% \text { Maximum } \\
\text { identity }\end{array}$ \\
\hline Mbi8 & wzxE1 & $\mathrm{E}$ & $\begin{array}{c}\text { Salmonella enterica subsp. } \\
\text { enterica serotype } \\
\text { Weltevreden str. } \\
\text { 2007-60-3289-1 }\end{array}$ & FR775224.1 & $\begin{array}{c}354,99 \% \\
3 e-171\end{array}$ & $98 \%$ \\
\hline Mbi25 & wzxE1 & $\mathrm{E}$ & $\begin{array}{c}\text { Salmonella enterica subsp. } \\
\text { enterica serotype } \\
\text { Weltevreden str. } \\
\text { 2007-60-3289-1 }\end{array}$ & FR775224.1 & $\begin{array}{c}348,99 \% \\
3 e-180\end{array}$ & $100 \%$ \\
\hline Pt12 & wzxE1 & E & $\begin{array}{c}\text { Salmonella enterica subsp. } \\
\text { enterica serotype } \\
\text { Weltevreden str. } \\
\text { 2007-60-3289-1 }\end{array}$ & FR775224.1 & $\begin{array}{c}253,96 \% \\
3 e-119\end{array}$ & $99 \%$ \\
\hline
\end{tabular}

serotype Choleraesuis, the sole serotype Enteritidis, and three serotype Weltevreden isolates were resistant to ampicillin; and two $S$. enterica serotype Typhimurium isolates, and one each from serotypes Heidelberg, Choleraesuis, Enteritidis, and Weltevreden, were resistant to sulfamethoxazole trimethoprim. In addition, the sole serotype Enteritidis was found to be resistant to ceftriaxone, ertapenem, tigecycline (Table 3), and ceftazidime (Table 4). Out of the 20 randomly selected S. enterica isolates, three (15\%) MDR serotypes were detected in the study, namely, Choleraesuis and Enteritidis, from non-accredited meat establishments and Weltevreden from an accredited meat establishment (Tables 2(a) and 2(b)). Among the three MDR isolates, S. enterica serotype Enteritidis was found to be resistant to 12 antibiotics of various antimicrobial classes including third generation cephalosporins ceftazidime and ceftriaxone, third generation aminoglycosides amikacin and gentamicin, as well as to the glycylcycline tigecycline (Tables 3 and 4). VITEK 2 AST also showed that all $20 \mathrm{~S}$. enterica isolates tested were susceptible to ceftazidime, cefepime, imipenem, meropenem, amikacin, and levofloxacin (Tables 2(a) and 2(b)). Moreover, VITEK 2 AST demonstrated that $S$. enterica isolates classified under the same serogroup had varying antibiograms as shown in Tables 2(a) and 2(b) for isolates Lt3 and Mbi8.

\section{Discussion}

AST is traditionally performed through the Kirby-Bauer disc diffusion assay. However, this method is laborious and prone to inconsistencies, subjectivity, and human error. The VITEK 2 system (bioMerieux) has revolutionized AST through its rapid and automated fluorescence-based technology that allows determination of minimum inhibitory concentration (MIC) by the analysis of growth kinetics of bacteria with antibiotics in test cards [12].

Among the antibiotics included in the VITEK 2 Gram negative susceptibility card used in the study, piperacillin/ tazobactam was suppressed from analysis while ESBL (extra spectrum $\beta$-lactamase) was not claimed by the machine since the latter is only considered relevant to Escherichia and Klebsiella species [13]. However, ESBL should not be anymore excluded from AST of $S$. enterica since an ESBL-producing $S$. enterica serotype Typhi has been isolated in the Philippines [17] and many of the isolates tested were found to be resistant to cephalosporins (Table 2(a)), the subsequent characteristic of possessing the enzyme ESBL.

VITEK 2 MIC interpretation guideline is based on Clinical and Laboratory Standards Institute [13]. Referring to Tables 2(a) and 2(b), MIC values and interpretations of almost all of the isolates to cefazolin, cefuroxime, cefuroxime axetil, cefoxitin, amikacin, and gentamicin, and of S. enterica serotype Enteritidis to ceftazidime were edited to resistant by the machine for the reason that these antibiotics may only appear active in vitro against $S$. enterica but are not effective in vivo (clinically) and should not be reported as susceptible. This editing of antibiograms based on inferred mechanisms is in agreement with the National Committee for Clinical Laboratory Standards [12].

This study is first to report ampicillin-resistant serotypes of S. enterica, namely, Typhimurium, Heidelberg, Choleraesuis, Enteritidis, and Weltevreden, isolated from tonsil and JLN tissues of slaughtered swine in the Philippines using VITEK 2 AST. The routine administration of ampicillin for gastroenteritis in both man and swine and its common use for sensitivity testing in diagnostic laboratories led to the occurrence of ampicillin-resistant $S$. enteric strains [18].

Amoxicillin/clavulanic acid-resistant serotypes of $S$. enterica, namely, Enteritidis and Weltevreden from tonsil and JLN tissues of slaughtered swine in Metro Manila, Philippines, were also first detected in this study using VITEK 2 AST (Table 2(a)). Resistance to cefazolin, cefuroxime, cefuroxime axetil, and cefoxitin was revealed by VITEK 2 AST in all 20 isolates tested in this study (Table 2(a)). This is the first report on resistance to the aforementioned cephalosporins of $S$. enterica serotypes Agona, Choleraesuis, Enteritidis, Heidelberg, Typhimurium, and Weltevreden obtained from tonsil and JLN tissues of slaughtered swine in the Philippines using VITEK 2 AST (Tables 3 and 4). It is remarkable to note that the said cephalosporins: cefazolin, cefuroxime, cefuroxime axetil, and cefoxitin are not commonly employed as therapeutic agents or growth promoters in livestock in the Philippines [19]. The emergence 

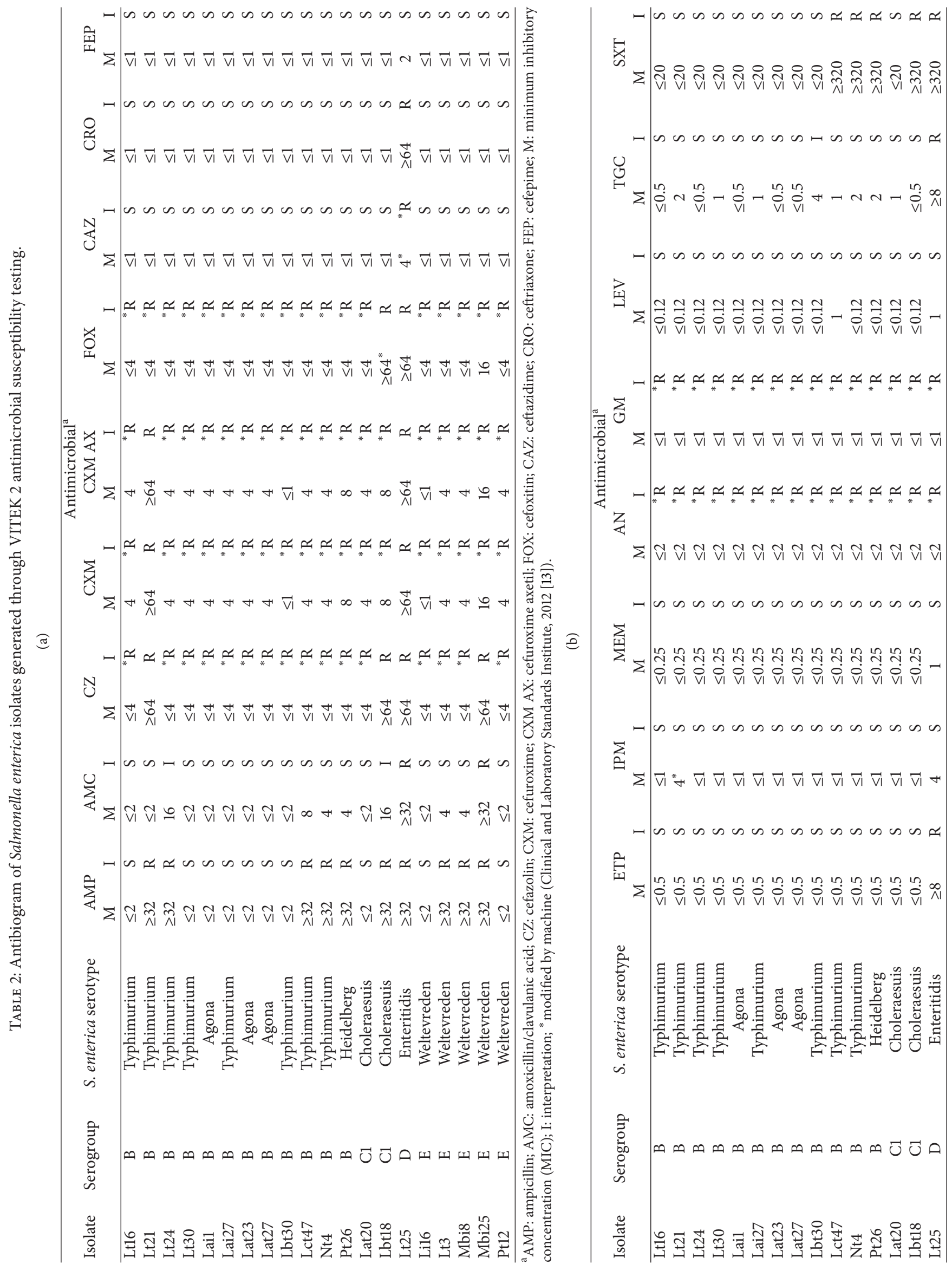


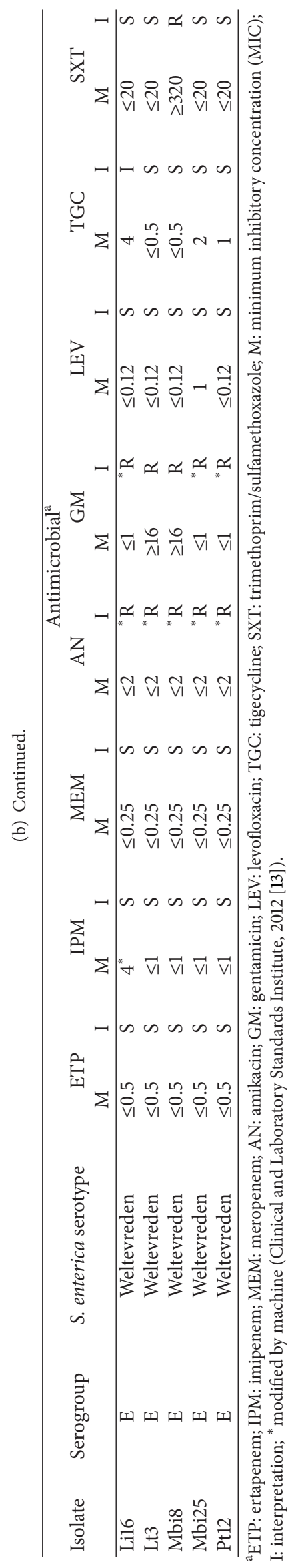


TABle 3: Distribution of in vitro antimicrobial resistance of Salmonella enterica serotypes isolated from swine at slaughter in Metro Manila.

\begin{tabular}{|c|c|c|c|c|c|c|c|c|c|c|c|}
\hline \multirow{2}{*}{$\begin{array}{l}\text { Serotype } \\
\text { (number tested) }\end{array}$} & \multicolumn{11}{|c|}{ Number of isolates resistant to the antimicrobial agents ${ }^{\mathrm{a}}$} \\
\hline & AMP & AMC & $\mathrm{CZ}$ & CXM & CXM AX & FOX & $\mathrm{CRO}$ & ETP & GM & TGC & SXT \\
\hline Choleraesuis (2) & 1 & & 1 & & & 1 & & & & & 1 \\
\hline Enteritidis (1) & 1 & 1 & 1 & 1 & 1 & 1 & 1 & 1 & & 1 & 1 \\
\hline Heidelberg (1) & 1 & & & & & & & & & & 1 \\
\hline $\begin{array}{l}\text { Typhimurium } \\
\text { (8) }\end{array}$ & 4 & & 1 & 1 & 1 & & & & & & 2 \\
\hline Weltevreden (5) & 3 & 1 & 1 & & & & & & 2 & & 1 \\
\hline
\end{tabular}

aAP: ampicillin; AMC: amoxicillin/clavulanic acid; CZ: cefazolin; CXM: cefuroxime; CXM AX: cefuroxime axetil; FOX: cefoxitin; CRO: ceftriaxone; ETP: ertapenem; GM: gentamicin; TGC: tigecycline; SXT: trimethoprim/sulfamethoxazole (Clinical and Laboratory Standards Institute, 2012 [13]).

TABLE 4: Distribution of in vivo antimicrobial resistance of Salmonella enterica serotypes isolated from swine at slaughter in Metro Manila.

\begin{tabular}{|c|c|c|c|c|c|c|c|}
\hline \multirow{2}{*}{$\begin{array}{l}\text { Serotype } \\
\text { (number tested) }\end{array}$} & \multicolumn{6}{|c|}{ Number of isolates resistant to the antimicrobial agents ${ }^{\mathrm{a}}$} & \multirow[b]{2}{*}{ GM } \\
\hline & $\mathrm{CZ}$ & $\mathrm{CXM}$ & CXM AX & FOX & CAZ & $\mathrm{AN}$ & \\
\hline Agona (3) & 3 & 3 & 3 & 3 & & 3 & 3 \\
\hline Choleraesuis (2) & 1 & 2 & 2 & 1 & & 2 & 2 \\
\hline Enteritidis (1) & & & & & 1 & 1 & 1 \\
\hline Heidelberg (1) & 1 & 1 & 1 & 1 & & 1 & 1 \\
\hline $\begin{array}{l}\text { Typhimurium } \\
\text { (8) }\end{array}$ & 7 & 7 & 7 & 8 & & 8 & 8 \\
\hline Weltevreden (5) & 4 & 5 & 5 & 5 & & 5 & 3 \\
\hline
\end{tabular}

${ }^{a}$ CZ: cefazolin; CXM: cefuroxime; CXM AX: cefuroxime axetil; FOX: cefoxitin; CAZ: ceftazidime; AN: amikacin; GM: gentamicin (Clinical and Laboratory Standards Institute, 2012 [13]).

of resistance to cephalosporins has been attributed to plasmid-mediated resistance to AmpC (CMY-2) $\beta$-lactamase [20].

The sole $S$. enterica serotype Enteritidis detected in this study exhibited resistance to third generation cephalosporins ceftazidime and ceftriaxone (Table 2(a)). In view of the high rate of resistance to fluoroquinolone ciprofloxacin, third generation cephalosporins such as ceftazidime and ceftriaxone are suggested as drugs of choice in the treatment of invasive nontyphoid Salmonella infections. Resistance to these antibiotics has been emerging due to production of various class A ESBLs and class C cephalosporinases in S. enterica strains [21]. Lee and coworkers [10] have detected ceftriaxone resistance only in S. enterica isolates under serogroups B and $\mathrm{C} 1$ from Taiwan. They did not detect ceftriaxone resistance in S. enterica isolates from the Philippines. This study is the first to report on in vitro resistance to ceftriaxone (Table 3 ) and in vivo resistance to ceftazidime (Table 4 ) of S. enterica serotype Enteritidis isolated from tonsil and JLN tissues of slaughtered swine in the Philippines using VITEK 2 AST.

Ampicillin, amoxicillin/clavulanic acid, and third generation cephalosporins are commonly used to treat complex salmonellosis [21]. The augmenting emergence of resistance to these antibiotics worldwide has brought about huge therapeutic challenge to animal and human medicine. Resistance to ertapenem was observed in isolate Lt 25 (serogroup D, serotype Enteritidis) (Table 2(b)). According to the study of Livermore and coworkers [22], ertapenem was the most active agent tested against members of the family Enterobacteriaceae including Salmonella spp. as compared to imipenem, cefepime, ceftriaxone, and piperacillin-tazobactam. Based on their broth microdilution experiments, Salmonella spp. isolates from Europe and Australia were susceptible to ertapenem. In the study of $\mathrm{Su}$ and coworkers [23], they detected a ceftriaxone and ciprofloxacin-resistant S. enterica serotype Typhimurium strain which developed carbapenem resistance during ertapenem treatment which they attributed to a single gene mutation in the organism. This is the first report on ertapenem resistance of $S$. enterica serotype Enteritidis from tonsil and JLN tissues of slaughtered swine in the Philippines using VITEK 2 AST.

Amikacin and gentamicin are aminoglycosides that bind to the bacterial $30 \mathrm{~S}$ ribosome and interfere with protein synthesis. These aminoglycosides have broader spectra of activity than streptomycin and kanamycin [24]. In 1992, Arboleda and coworkers [25] isolated a gentamicin-sensitive Salmonella spp. from a piglet in Laguna, Philippines, whereas Maluping in 2005 [26] isolated gentamicin-resistant S. enterica serotype Choleraesuis also from the same animal in Bulacan, Philippines. The result obtained in the present study reflects the increasing resistance of $S$. enterica to gentamicin as two gentamicin-resistant $S$. enterica serotype Weltevreden isolates were detected for the first time from tonsil and JLN tissues of slaughtered swine in the Philippines using VITEK 2 AST (Table 3). In vivo resistance against amikacin was found in all $20 \mathrm{~S}$. enterica isolates from tonsil and JLN tissues of 
slaughtered swine, specifically in serotypes Agona, Choleraesuis, Enteritidis, Heidelberg, Typhimurium, and Weltevreden for the first time in the Philippines using VITEK 2 AST (Table 4). This finding is novel and needs further study since aminoglycoside phosphotransferase $\mathrm{APH}\left(3^{\prime}\right)$-I detected in $S$. enterica generates resistance only to kanamycin, neomycin, lividomycin, paromomycin, and ribostamycin [24].

The most alarming resistance of multidrug isolates found was to tigecycline, a broad-spectrum derivative of minocycline and a member of the novel class glycylcyclines [27]. It is considered a promising drug for treating complex infections since it has a bacteriostatic mode of action against a broad spectrum of aerobic and anaerobic, atypical Grampositive and Gram-negative organisms, and even MDR ESBL-expressing Enterobacteriaceae and carbapenem-resistant strains [27-30]. It is said to circumvent efflux and ribosomal protection, the two most frequent genetic mechanisms of tetracycline resistance. It is also unaffected by the presence of coresistance to unrelated antimicrobials, such as $\beta$-lactams, aminoglycosides, and quinolones [30].

Fritsche and coworkers [31] found that $95.7 \%$ of all Enterobacteriaceae strains tested including Salmonella spp. were susceptible to tigecycline. In 2010, Hentschke and coworkers [27] isolated tigecycline-resistant S. enterica serotype Hadar with MIC of $16 \mu \mathrm{g} / \mathrm{mL}$ from a human patient in Germany. Results obtained in the present study are remarkably in contrast to the findings of Fritsche and coworkers [31] but in agreement with that of Hentschke and coworkers [27] implicating the augmenting emergence of S. enterica strains. Referring to Table 2(b), VITEK 2 AST revealed resistance of isolate Lt25 (serogroup D, serotype Enteritidis) to tigecycline. This is the first report in the world on tigecycline-resistant S. enterica serotype Enteritidis with MIC of $\geq 8 \mu \mathrm{g} / \mathrm{mL}$ from animal source using VITEK 2 AST. This finding is an important contribution to the global data bank of MDR tigecycline-resistant $S$. enterica serotypes. Further characterization of this novel tigecycline-resistant $S$. enterica strain should be consequently done as this may reveal genetic basis of resistance and factors involved in it.

Chu and coworkers [32] isolated trimethoprim resistantS. enterica serotype Virchow from human in Taiwan. VITEK 2 AST performed in this study revealed sulfamethoxazole trimethoprim-resistant $S$. enterica serotypes Typhimurium, Choleraesuis, Enteritidis, and Weltevreden isolates (Tables 2(b) and 3). This result is of huge relevance since this antimicrobial is commonly administered to treat salmonellosis in the Philippines. In 2005, Maluping [26] isolated sulfamethoxazole trimethoprim-resistant $S$. enterica serotype Choleraesuis from swine in Bulacan, Philippines. The present study is consistent with the latter as sulfamethoxazole trimethoprimresistant $S$. enterica serotype Choleraesuis was isolated from tonsil tissues of slaughtered swine in Metro Manila, Philippines. Additionally, this study is the first to report on detection of sulfamethoxazole trimethoprim-resistant S. enterica serotypes, namely, Enteritidis, Heidelberg, Typhimurium, and Weltevreden, from tonsil and JLN tissues of slaughtered swine in the Philippines using VITEK 2 AST. Due to increasing resistance of nontyphoid $S$. enterica serotypes to sulfamethoxazole trimethoprim, it is not anymore considered as appropriate treatment against invasive salmonellosis [33].

Multiple drug resistance is defined as resistance to three or more classes of antimicrobials [31]. MDR Salmonella spp. isolates have been reported since the 1960s [11,30, 32, 33]. This could be attributed to the use of high levels of combinations of antibiotics without adequate supervision or veterinary advice that is common in small-scale hog-raising in the country [19]. Detection of MDR Salmonella spp. isolates from Philippine hogs thus deserves great attention.

Cephalosporins and fluoroquinolones are recommended for treatment against strains resistant to ampicillin and sulfamethoxazole trimethoprim [33]. Although isolates resistant to cephalosporins have been detected in the present study, $100 \%$ susceptibility of all isolates tested to levofloxacin, a third generation fluoroquinolone was noted (Table 2(b)).

\section{Conclusion}

The results obtained from this study confirm the role of swine as reservoir of MDR S. enterica. Moreover, this study detected for the first time in the world, MDR tigecyclineresistant S. enterica serotype Enteritidis from animal source using VITEK 2 AST that poses huge therapeutic challenge to animal and human medicine. Hence, there is a need for continuing regulation of antimicrobial use and mandatory antimicrobial susceptibility testing in food animals.

\section{Conflict of Interests}

The authors declare that there is no conflict of interests regarding the publication of this paper.

\section{Acknowledgments}

This work was supported by Grants from the Office of the Vice Chancellor for Research and Development of the University of the Philippines Diliman, Office of the Vice President for Academic Affairs of the University of the Philippines System, and the Department of the AgricultureBiotechnology Program Implementation Unit.

\section{References}

[1] R. S. Hendriksen, M. Mikoleit, C. Kornschober et al., "Emergence of multidrug-resistant Salmonella concord infections in Europe and the United States in children adopted from Ethiopia, 2003-2007,' The Pediatric Infectious Disease Journal, vol. 28, no. 9, pp. 814-818, 2009.

[2] E. L. Hohmann, "Nontyphoidal salmonellosis," Clinical Infectious Diseases, vol. 32, no. 2, pp. 263-269, 2001.

[3] CDC, "General information on Salmonella," Atlanta, Georgia, USA, 2012, http://www.cdc.gov/Salmonella/general/index .html.

[4] W. A. Gebreyes, P. R. Davies, P. K. Turkson et al., "Characterization of antimicrobial-resistant phenotypes and genotypes among Salmonella enterica recovered from pigs on farms, from transport trucks, and from pigs after slaughter," Journal of Food Protection, vol. 67, no. 4, pp. 698-705, 2004. 
[5] B. Nowak, T. von Müffling, S. Chaunchom, and J. Hartung, "Salmonella contamination in pigs at slaughter and on the farm: a field study using an antibody ELISA test and a PCR technique," International Journal of Food Microbiology, vol. 115, no. 3, pp. 259-267, 2007.

[6] V. Labro, "Salmonella infection in pigs rises," Metro Manila, Philippines, 2009, http://services.inquirer.net/print/print.php? article_id=20090201-186729.

[7] J. B. Zabala, D. A. Mendoza, F. Caput, M. C. Roces, and M. White, "Salmonella food poisoning in Benguet," Philippine Journal of Microbiology Infectious Diseases, vol. 22, pp. 5-7, 1993.

[8] A. Lopez, "DoH eyes Salmonella in Tondo food poisoning," Metro Manila, Philippines, 2008, http://newsinfo.inquirer.net/ breakingnews/metro/view20080925-162897/DoH-eyes-Salmonella-in-Tondo-food-poisoning.

[9] C. Reyes-Estrope, "Salmonella found cause of food poisoning," Metro Manila, Philippines, 2011, http://newsinfo.inquirer.net/ 17168/Salmonella-found-cause-of-bulacan-food-poisoning.

[10] H. Y. Lee, L. H. Su, M. H. Tsai et al., "High rate of reduced susceptibility to ciprofloxacin and ceftriaxone among nontyphoid Salmonella clinical isolates in Asia," Antimicrobial Agents and Chemotherapy, vol. 53, no. 6, pp. 2696-2699, 2009.

[11] H. J. Yoon, S. H. Cho, and S. H. Kim, "A case of multidrug-resistant Salmonella enterica serovar typhi treated with a bench to bedside approach," Yonsei Medical Journal, vol. 50, no. 1, pp. 147151, 2009.

[12] D. M. Livermore, M. Struelens, J. Amorim et al., "Multicentre evaluation of the VITEK 2 advanced expert system for interpretive reading of antimicrobial resistance tests," Journal of Antimicrobial Chemotherapy, vol. 49, no. 2, pp. 289-300, 2002.

[13] Clinical and Laboratory Standards Institute, Performance Standards for Antimicrobial Susceptibility Testing; Twenty-Second Informational Supplement, Clinical Laboratory Standards Institute, Wayne, Pa, USA, 2012.

[14] M. E. E. Nori and K. L. Thong, "Differentiation of Salmonella enterica based on PCR detection of selected somatic and flagellar antigens," African Journal of Microbiology Research, vol. 4, no. 9, pp. 871-876, 2010.

[15] C. H. Chiu and J. T. Ou, "Rapid identification of Salmonella serovars in feces by specific detection of virulence genes, invA and $s p v C$, by an enrichment broth culture- multiplex PCR combination assay," Journal of Clinical Microbiology, vol. 34, no. 10, pp. 2619-2622, 1996.

[16] T. A. Hall, "BioEdit: a user-friendly biological sequence alignment editor and analysis program for Windows 95/98/NT," Nucleic Acids Symposium Series, vol. 41, pp. 95-98, 1999.

[17] N. Al Naiemi, B. Zwart, M. C. Rijnsburger et al., "Extendedspectrum-beta-lactamase production in a Salmonella enterica serotype typhi strain from the Philippines," Journal of Clinical Microbiology, vol. 46, no. 8, pp. 2794-2795, 2008.

[18] L. R. Baldrias and A. K. Raymundo, "Antimicrobial resistance profile of local campylobacter jejuni recovered from ceca of dressed chickens of commercial and backyard raisers in Laguna, Philippines," Philippine Journal of Veterinary Medicine, vol. 46, no. 2, pp. 87-94, 2009.

[19] T. T. Huynh, A. J. Aarnink, A. Drucker, and M. W. Verstegen, "Pig production in Cambodia, Laos, Philippines, and Vietnam: a review," Asian Journal of Agriculture and Development, vol. 4, pp. 69-90, 2007.

[20] P. D. Fey, T. J. Safranek, M. E. Rupp et al., "Ceftriaxone-resistant Salmonella infection acquired by a child from cattle," The New
England Journal of Medicine, vol. 342, no. 17, pp. 1242-1249, 2000.

[21] M. de Toro, Y. Sáenz, E. Cercenado et al., "Genetic characterization of the mechanisms of resistance to amoxicillin/clavulanate and third-generation cephalosporins in Salmonella enterica from three Spanish hospitals," International Microbiology, vol. 14, no. 3, pp. 173-181, 2011.

[22] D. M. Livermore, M. W. Carter, S. Bagel et al., "In vitro activities of ertapenem (MK-0826) against recent clinical bacteria collected in Europe and Australia," Antimicrobial Agents and Chemotherapy, vol. 45, no. 6, pp. 1860-1867, 2001.

[23] L. H. Su, T. L. Wu, and C. H. Chiu, "Development of carbapenem resistance during therapy for non-typhoid Salmonella infection," Clinical Microbiology and Infection, vol. 18, no. 4, pp. E91-E94, 2012.

[24] S. B. Vakulenko and S. Mobashery, "Versatility of aminoglycosides and prospects for their future," Clinical Microbiology Reviews, vol. 16, no. 3, pp. 430-450, 2003.

[25] N. P. Arboleda, M. F. Vizmanos, E. M. Valera, and E. B. Brana, "Septicemic salmonellosis in a piglet," Philippine Journal of Veterinary Medicine, vol. 29, no. 2, pp. 57-58, 1992.

[26] R. P. Maluping, "Pneumonia associated with Salmonella Choleraesuis infection in a piglet," Philippine Journal of Veterinary Medicine, vol. 42, no. 1, pp. 53-55, 2005.

[27] M. Hentschke, M. Christner, I. Sobottka, M. Aepfelbacher, and H. Rohde, "Combined ramR mutation and presence of a Tn1721associated tet(A) variant in a clinical isolate of Salmonella enterica serovar hadar resistant to tigecycline," Antimicrobial Agents and Chemotherapy, vol. 54, no. 3, pp. 1319-1322, 2010.

[28] A. C. Fluit, A. Florijn, J. Verhoef, and D. Milatovic, "Presence of tetracycline resistance determinants and susceptibility to tigecycline and minocycline," Antimicrobial Agents and Chemotherapy, vol. 49, no. 4, pp. 1636-1638, 2005.

[29] D. J. Hoban, S. K. Bouchillon, B. M. Johnson, J. L. Johnson, and M. J. Dowzicky, "In vitro activity of tigecycline against 6792 Gram-negative and Gram-positive clinical isolates from the global Tigecycline Evaluation and Surveillance Trial (TEST Program, 2004)," Diagnostic Microbiology and Infectious Disease, vol. 52, no. 3, pp. 215-227, 2005.

[30] T. Horiyama, E. Nikaido, A. Yamaguchi, and K. Nishino, "Roles of Salmonella multidrug efflux pumps in tigecycline resistance," Journal of Antimicrobial Chemotherapy, vol. 66, no. 1, pp. 105110, 2011.

[31] T. R. Fritsche, P. A. Strabala, H. S. Sader, M. J. Dowzicky, and R. N. Jones, "Activity of tigecycline tested against a global collection of Enterobacteriaceae, including tetracycline-resistant isolates," Diagnostic Microbiology and Infectious Disease, vol. 52, no. 3, pp. 209-213, 2005.

[32] C. Chu, B. Doublet, Y. L. Lee et al., "Salmonella genomic island $1-J$ variants associated with change in the antibiotic resistance gene cluster in multidrug-resistant Salmonella enterica serovar Virchow isolated from humans, Taiwan, 2004-2006," Clinical Microbiology and Infection, vol. 18, no. 1, pp. 47-53, 2012.

[33] L. H. Su, C. H. Chiu, C. Chu, and J. T. Ou, "Antimicrobial resistance in nontyphoid Salmonella serotypes: a global challenge," Clinical Infectious Diseases, vol. 39, no. 4, pp. 546-551, 2004. 

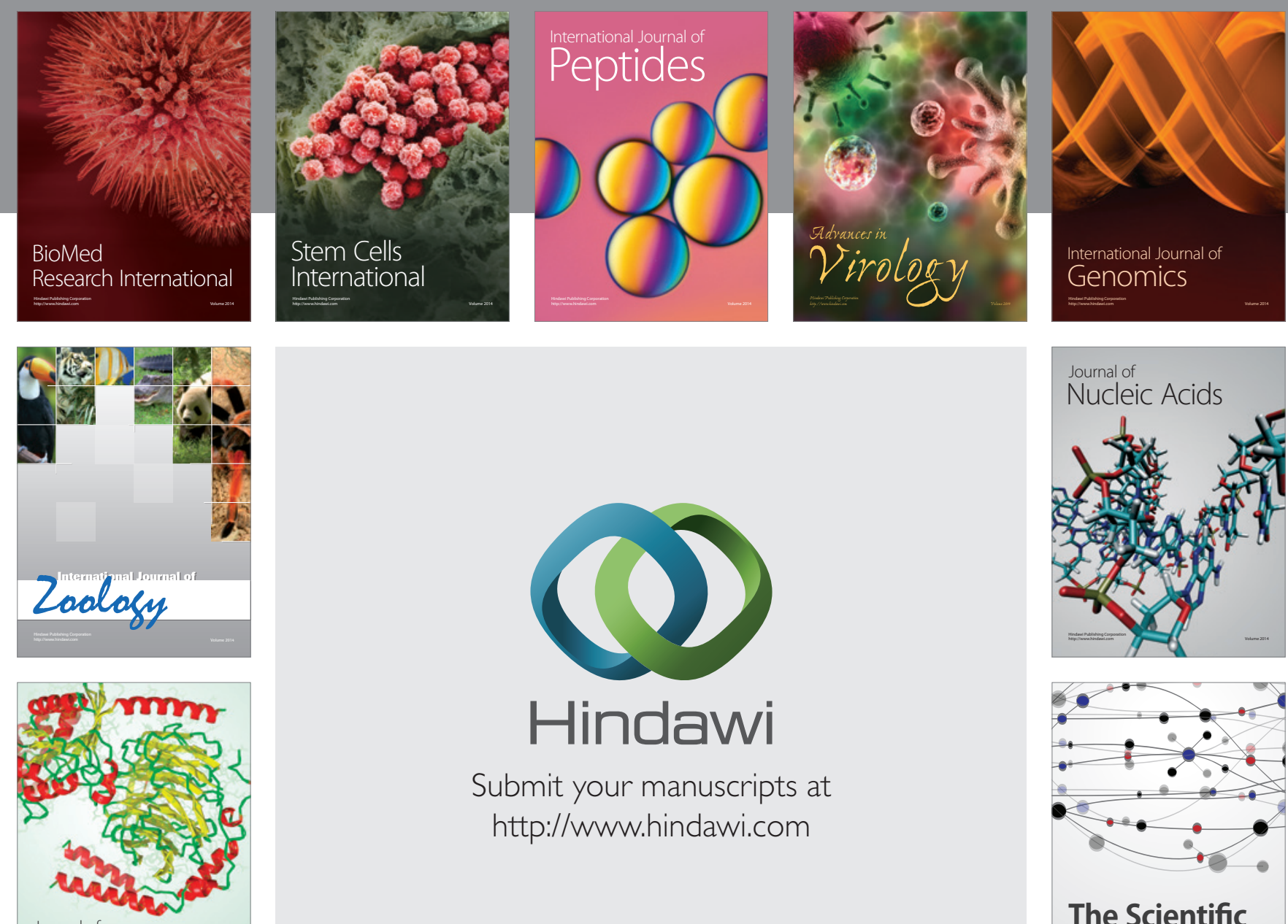

Submit your manuscripts at

http://www.hindawi.com

Journal of
Signal Transduction
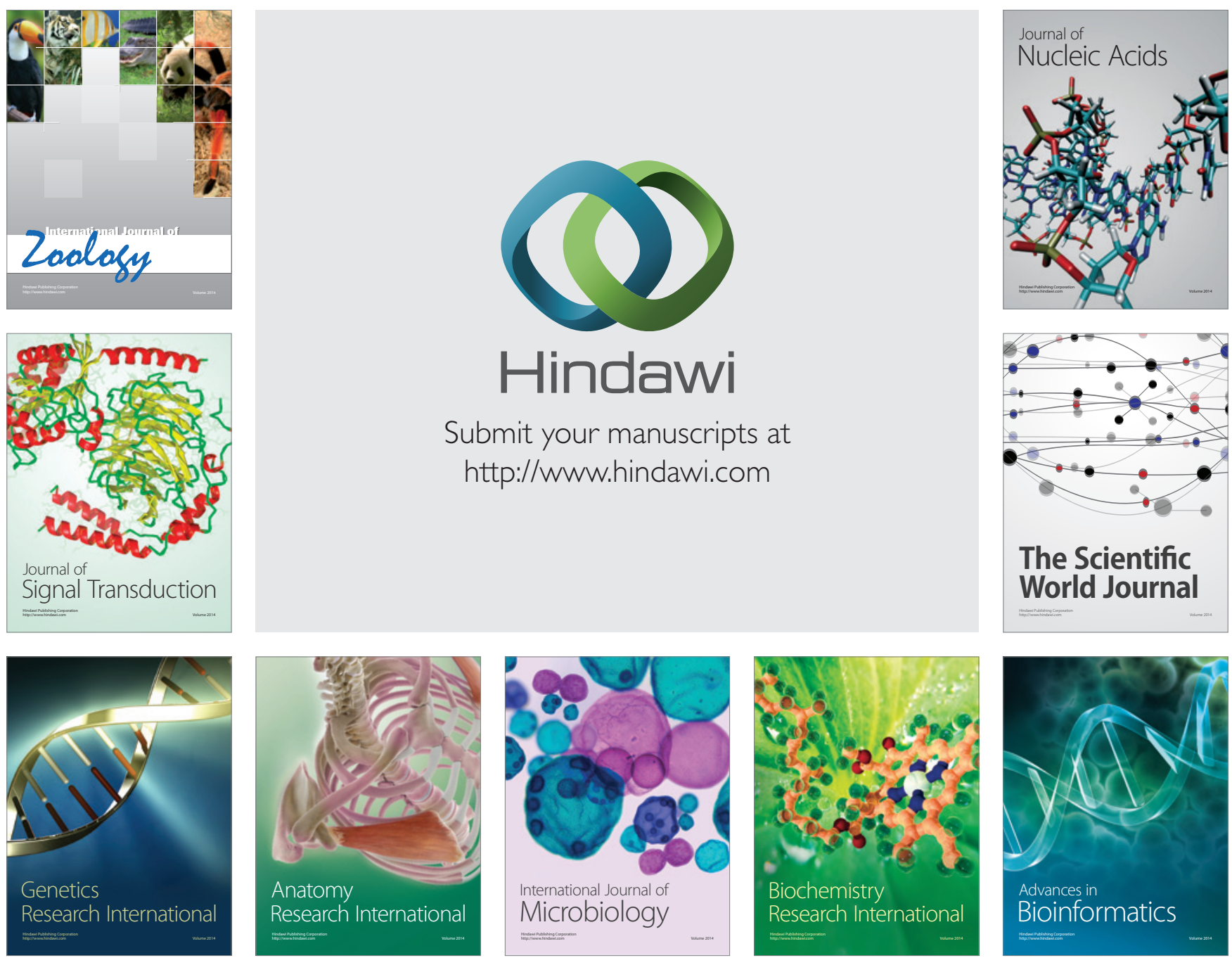

The Scientific World Journal
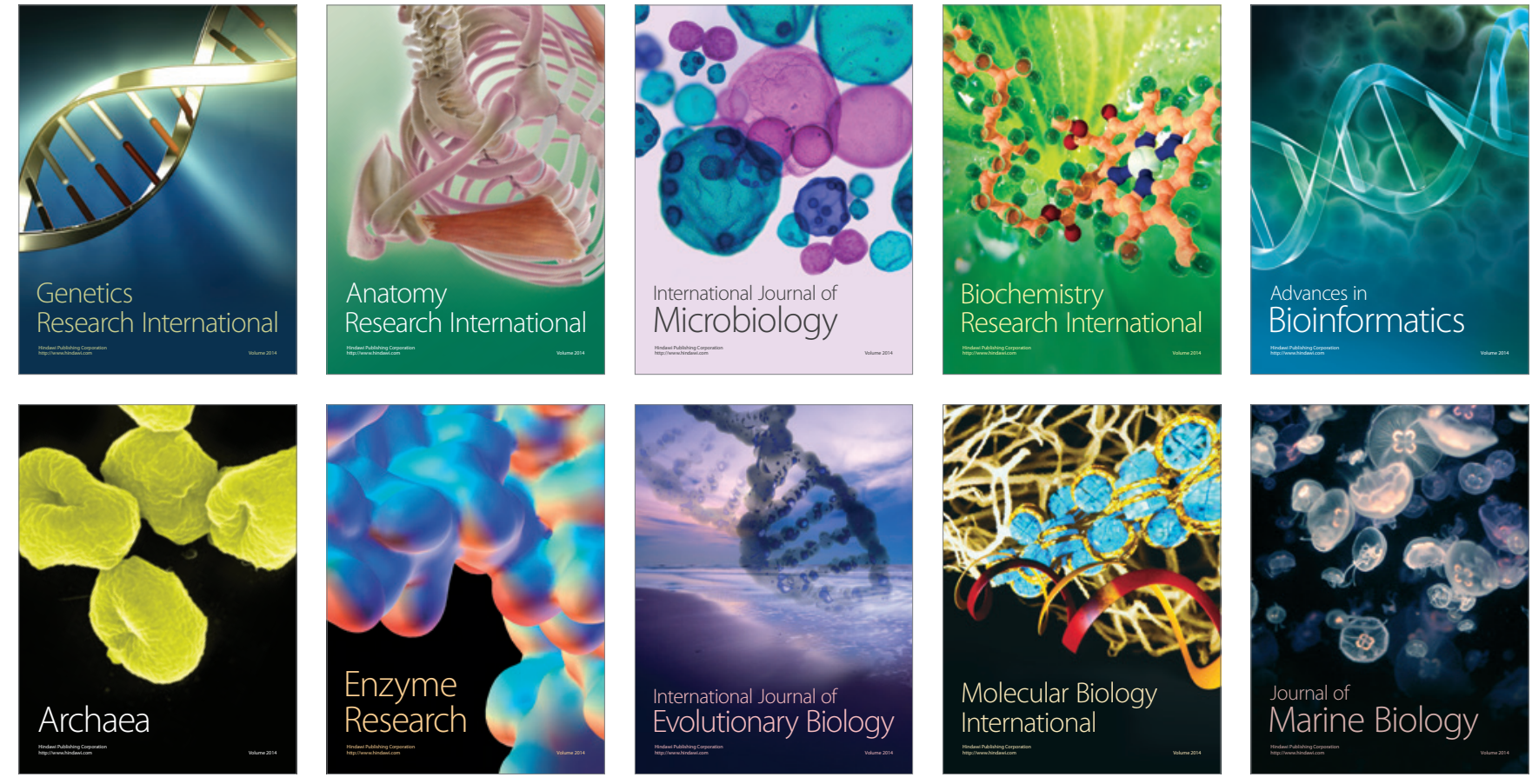